\title{
WiMAX Based Monitoring Network for a Utility Company: a case study
}

\author{
Margot Deruyck*, Erik Vanhauwaert, Daan Pareit, Bart Lannoo, Wout Joseph, Ingrid Moerman, Luc \\ Martens \\ Dept. of Information Technology (INTEC), Ghent University/IBBT, Gaston Crommenlaan 8, 9050 Ghent, Belgium \\ \{margot.deruyck,erik.vanhauwaert, daan.pareit, bart.lannoo, wout.joseph, luc.martens\}@intec.ugent.be
}

\begin{abstract}
As the network of a power distribution company can be very large, maintaining such a network is not only very timeconsuming but also very costly, especially when failures occur. A huge amount of effort could be saved by monitoring the substations remotely which allows, amongst others, to trace failures more efficiently. In this study, such a monitoring network is designed based on WiMAX. To the best of the authors' knowledge, this study differs from previous studies by combining both coverage and cost calculations. Firstly, the number of base stations needed to cover the considered area is determined. Therefore, link budget calculations are performed to obtain the ranges of the base stations. Secondly, the cost to install and maintain the network is determined using the results of the first step.

A cost of approximately 6.5 EUR was found per $\mathrm{km}^{2}$ that needs to be covered. This result is very sensitive to possible changes of the technical parameters, which can lead to cost fluctuations between $33.5 \%$ and $3007 \%$. Changes in the cost parameters have, however, less impact on the total cost than the technical parameters.
\end{abstract}

\section{* Correspondence}

Dept. of Information Technology (INTEC), Ghent University/IBBT, Gaston Crommenlaan 8, 9050 Ghent, Belgium,

margot.deruyck@intec.ugent.be.

\section{INTRODUCTION}

Power distribution companies typically have a large network with a hierarchical structure of different types of substations, even to the farthest corners of the country. The architecture of such a network is shown in Fig. 1. An important element in this network is the substation. A substation transforms power from one voltage level to another (lower) level. Two types of substations can be identified: transformer and distribution substations. The "large" transformer substations (typically 50x50 $\mathrm{m}^{2}$ ) transform voltages of 150 and $36 \mathrm{kV}$ to $11 \mathrm{kV}$ and deliver the power to the distribution substations [1]. The distribution substations transform the voltage level then from $11 \mathrm{kV}$ to 220 or $230 \mathrm{~V}$ and deliver the electricity to a number of houses or buildings [2]. The distribution substations can thus be found in almost every street, resulting in a total of 40,000 substations to provide electricity for a region in Flanders (ca. $10,000 \mathrm{~km}^{2}$ with ca. 4.8 million inhabitants). Maintaining such a network of substations is not only time-consuming but also very costly, especially when failures occur. A huge amount of effort could be saved by monitoring the substations remotely. In this way, failures could be traced more efficiently and faster, instead of waiting until a technician has established which substation has failed by going on the spot. As the failure can be traced more quickly, the time to solve the problem is reduced, which keeps the customers satisfied and reduces the operational costs.

In this paper, a monitoring network for a power distribution company is designed based on WiMAX (Worldwide Interoperability for Microwave Access) [3]. WiMAX is introduced as a wireless technology for broadband connection and thus a perfect wireless alternative for the wired last mile connection. Companies around the world provide commercial networks based on WiMAX, not only to cities, but also to the faraway areas which were never reached by wired lines [4]. Although some operators in Russia and Malaysia intend to switch their networks from WiMAX to LTE (Long Term Evolution) as the latter allows to achieve a higher throughput $[5,6,7]$, there are also cases where WiMAX is successful such as in the city of Houston, USA, which decided to deploy a municipal wireless network based on WiMAX for their city services [8]. This network allows to control traffic signals and school zone flashers remotely, to monitor water meters, to replace expensive wired lines, to make excess bandwidth available to enable 


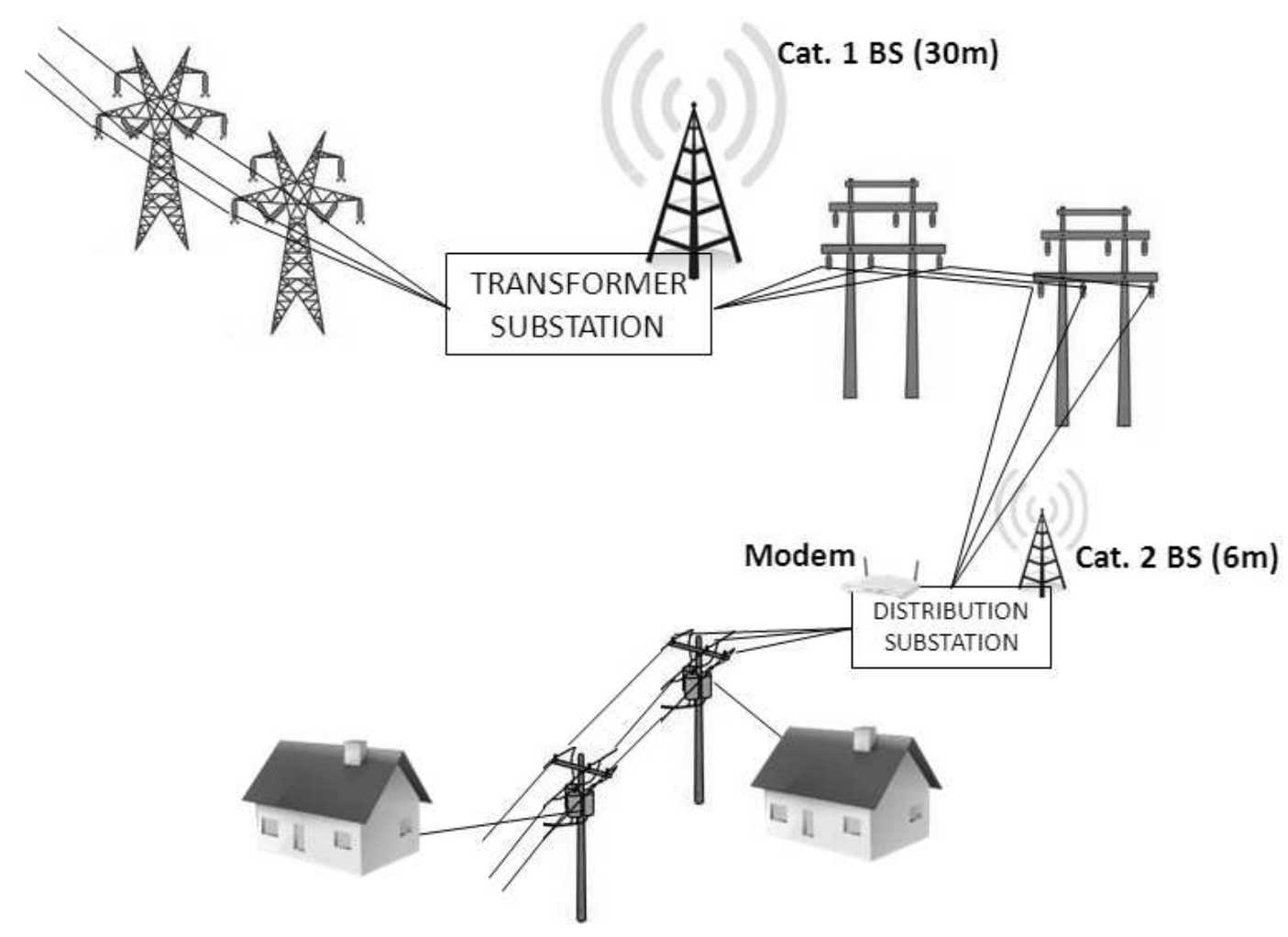

Figure 1. Architecture of a power distribution network.

free Internet services for the city residents in underserved and underprivileged communities (i.e., public computer centers for children), etc. The reason why Houston selected WiMAX as technology is that WiMAX allows huge savings on infrastructure expenses, while it can be easily and remotely managed to reduce the operational costs. As an extra, it permits to provide wireless access to the residents as well. Therefore, it might be interesting to investigate if WiMAX is a suitable technology for the monitoring network of a power distribution company as most monitoring networks are based on GPRS (General Packet Radio Services) [9, 10]. In [11] and [12], WiMAX is used as an alternative for GPRS, however, no cost calculation was made. Only range and coverage were calculated in $[11,12]$. As both the cost and the coverage are never been investigated at the same time, according to the authors knowledge, it is interesting to investigate the consequences of choosing WiMAX as wireless technology for the monitoring network. Here, it is determined how many WiMAX base stations (BSs) are needed by calculating the coverage of each WiMAX base station. Also the cost to install and maintain the monitoring network is determined. Finally, it is investigated how sensitive the results are to changes in both the technical and cost parameters. Note that in this study a power distribution company is considered, but the results can also be applied to any other utility company as their networks are built similarly to that of a power distribution company.
The outline of this paper is as follows. In Section 2, a technical overview of WiMAX is given. Section 3 discusses the assumptions made and the proposed scenario. In Section 4, it is studied how many WiMAX base stations are needed for the monitoring network and how sensitive the results are for changes in the technical parameters. In Section 5, the costs for the monitoring network are determined based on the results of Section 4 . Furthermore, it is investigated how sensitive the results are to changes in the cost parameters. Finally, Section 6 gives the conclusions of this study.

\section{TECHNICAL OVERVIEW OF WIMAX}

WiMAX is a wireless technology for broadband communication, mainly based on the IEEE 802.16 standard. Technology details and product certification are specified by the WiMAX Forum to support interoperability between different vendors.

Two important system profiles can be distinguished: Fixed WiMAX [13] and Mobile WiMAX [3], both trademarks of the WiMAX Forum. Fixed WiMAX supports fixed, nomadic, and portable services, while Mobile WiMAX is developed for mobile wireless applications and adds mobility to WiMAX. Currently, Mobile WiMAX has the most commercial interest and is being actively developed and deployed. 
Mobile WiMAX (Release 1.5) is used in this study, as most of the current WiMAX products are supporting this standard [14]. Of course, this does not imply that the client nodes need to be "mobile" or on the move. In fact, in this case, all client nodes will remain in their place and the antennas are not moving.

\section{ASSUMPTIONS AND SCENARIO}

In this section, the area to be covered and the network architecture are presented. Furthermore, the determination of the number of base stations needed and the bit rate requirement are discussed.

\subsection{Area to be covered}

The area to be covered is situated in Flanders, Belgium and has a surface of ca. $10,000 \mathrm{~km}^{2}$ counting ca. 4.8 million inhabitants [15]. For simplicity, this area will be called "Flanders".

Within this area, two region types can be defined from a propagation based point of view: suburban regions (cities in "Flanders" such as Antwerp, Ghent, etc.) and rural areas. The surface of the suburban area is about $10 \%$ (ca. 1,000 $\mathrm{km}^{2}$ ) of the surface of "Flanders", and counts $28 \%$ of the population (ca. 1.4 million inhabitants). Note that examples of urban areas are New York, Tokyo, Los Angeles, etc.; and that Belgian cities thus not belong to that category. The remaining area of "Flanders" can be considered as rural. This distinction between suburban and rural areas is important for the range and coverage calculations of Section 4.

\subsection{Network architecture}

As mentioned above, 40,000 distribution substations are needed to provide "Flanders" with electricity from which 10,000 are situated in the suburban area and 30,000 in the rural area. To deliver electricity to the distribution substations at the correct power level, 600 transformer substations are also needed, from which 150 are situated in the suburban area and 450 in the rural area. As all of the distribution substations need to be monitored, base stations have to be installed through "Flanders". The base station will be attached to the existing (transformer and distribution) substations of the power network.

If necessary, a transformer substation can be extended with a Category 1 (Cat. 1) base station which has an antenna height of $30 \mathrm{~m}$ as shown in Fig. 1. A $30 \mathrm{~m}$ pylon is thus required for these base stations. Furthermore, it is assumed that all of the transformer substations are equipped with a fibre for the backhaul connection. Analogously, if necessary, a distribution substation can be extended with a Category 2 (Cat. 2) base station also shown in Fig. 1. The antenna of a Cat. 2 BS will be positioned on the roof of the substation with a height of $6 \mathrm{~m}$. This height is necessary to cover the distance between the distribution substations as discussed in Section 4.2.1. The Cat. 2 BSs will be either directly connected to a Cat. $1 \mathrm{BS}$, equipped with a backhaul connection, or indirectly by intermediate Cat. 2 BSs as shown in Fig. 2. The full grey line in Fig. 2 indicates the physical (i.e. area where utility station delivers electricity) range of the substation, while the grey dotted line indicates the wireless range of the Cat. 1 BS installed on this substation. As shown in Fig. 2, the Cat. 2 BSs will need to hop to each other until they reach a Cat. 2 BS that is directly connected to a Cat. $1 \mathrm{BS}$ because the Cat. 1 BSs are the only BSs that have a connection with the backhaul network as discussed above. For the hopping, the Cat. 2 BS behaves as a relay station (RS) and in this way a mesh network will be formed. Noted that the mesh/relay technology is only supported from Mobile WiMAX release 2.0.

An overview of the two categories of base stations is given in Table I. Note that the only difference between the Cat. 1 and Cat. 2 base stations is the antenna height and the backhaul connection. A base station typically consists of the following equipment: the transceiver, the power amplifier, the digital signal processing, the rectifier, and the air conditioning [16].

Furthermore, the distribution of the different substations (i.e., how the different substations are spread over the suburban and rural area of "Flanders") approaches a uniform distribution. This is evident because such a distribution is the most convenient approach of the network for a utility company. In this way, they can cover "Flanders" with a minimal number of substations and thus with a minimal cost. For estimating the WiMAX coverage, an important input parameter is the distance between the different base station locations. To calculate this average distance, the rural area and the suburban area are divided by the number of transformer (resp. distribution) substations. This gives us the surface $\mathrm{S}$ (= $\mathrm{A} / \mathrm{N}$ with $\mathrm{A}$ the surface of the area and $\mathrm{N}$ the number of substations) of the coverage of one distribution (resp. transformer) substation in the rural and suburban area. Assuming that $\mathrm{S}$ corresponds with a circle, the radius $\mathrm{R}\left(=\pi \cdot(S / 2)^{2}\right)$ of the circle can be determined. This radius corresponds with the average distance between two transformer (resp. distribution) substations. The average distance between two transformer substations amounts to $2.9 \mathrm{~km}$ in suburban area and to $5.0 \mathrm{~km}$ in rural area. For the distribution substations, an average distance of $356.8 \mathrm{~m}$ and $618.0 \mathrm{~m}$ is found in, respectively, the suburban and the rural area.

Finally, each distribution substation is equipped with a WiMAX modem to transfer the monitoring data from these substations (Fig. 1). The antenna of these modems is placed at a height of $2.5 \mathrm{~m}$.

\subsection{Coverage requirement}

In a first step, it is determined how much Cat. 1 BSs are needed to cover the rural (resp. suburban) area of "Flanders". The number of base stations \#BS needed to 


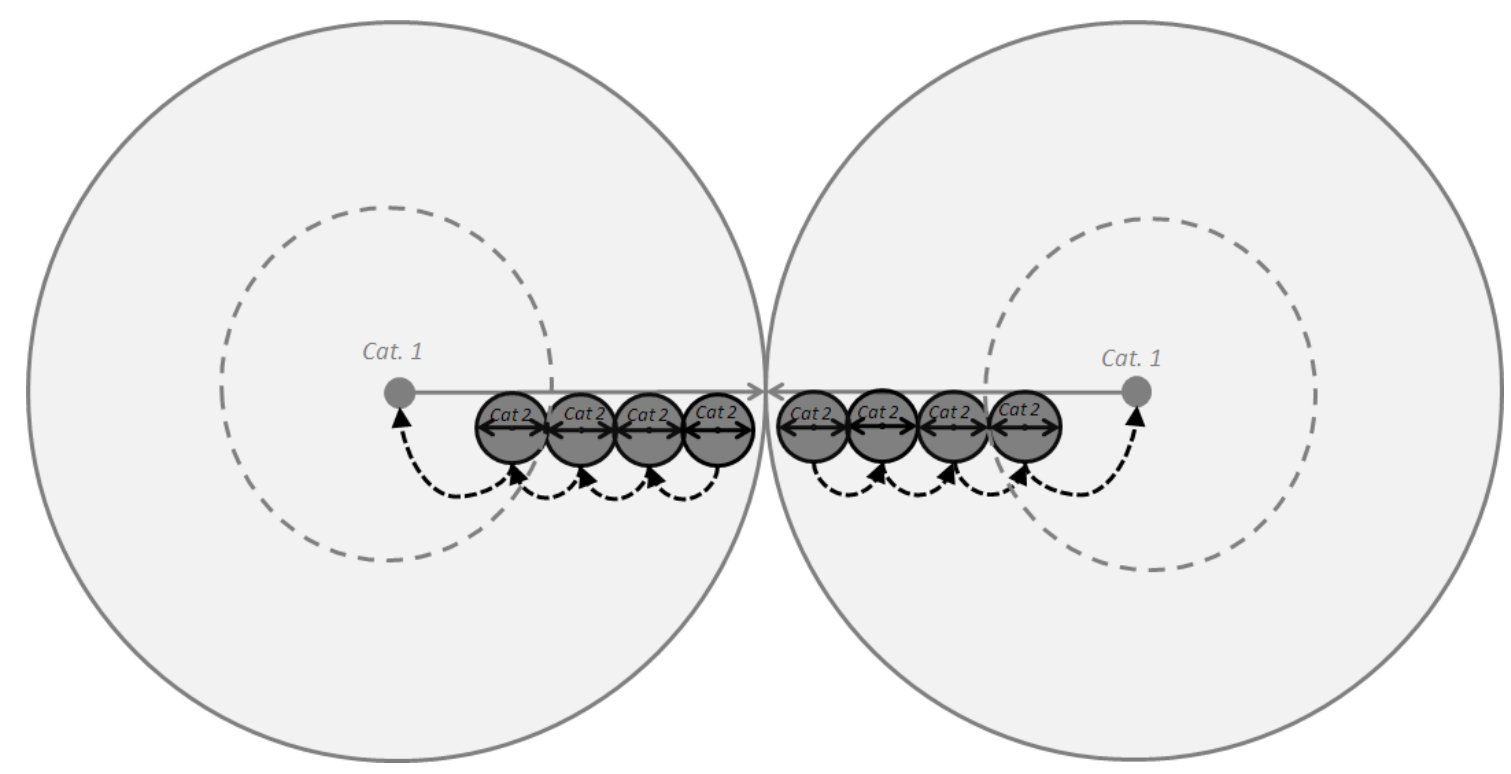

Figure 2. Architecture of the WiMAX network. The grey full line shows that the physical (not wireless) range of the Cat. 1 BS, while the grey dotted line shows the wireless range of the Cat. $1 \mathrm{BS}$.

\begin{tabular}{|l|c|c|}
\hline & Cat. 1 BS & Cat. 2 BS \\
\hline No. of possible rural locations & 450 & 30,000 \\
\hline No. of possible suburban locations & 150 & 10,000 \\
\hline Antenna height & $30 \mathrm{~m}$ & $6 \mathrm{~m}$ \\
\hline Connection backhaul & Fibre & $\begin{array}{c}\text { (i) Directly to Cat. 1 BS } \\
\text { (ii) Indirectly by intermediate Cat. 2 BS }\end{array}$ \\
\hline
\end{tabular}

Table I. Characteristics of the two categories of base stations.

cover an area with surface $\mathrm{S}$ (in $\mathrm{km}^{2}$ ) is then:

$$
\# B S=\left\lceil\frac{S}{\pi \cdot R^{2}}\right\rceil
$$

with $\mathrm{R}$ the range of the base station (in $\mathrm{km}$ ) and $\lceil\cdot\rceil$ the ceil function. How to determine R is discussed in Section 4.

If the number of Cat. $1 \mathrm{BSs}$ needed is lower or equal than the number of transformer substations, the calculation is stopped as the solution is found. Otherwise, all the available transformer substations will be equipped with a Cat. $1 \mathrm{BS}$ and it is determined how large the part of the rural (resp. suburban) area is that is not yet covered by Cat. 1 BS. It is then determined how much Cat. 2 BSs are needed to cover the resulting part of the area.

Note that in this study the actual position of the substations and the topology of these positions are not yet taken into account. The purpose of this study is to make an estimation of the order of magnitude for the cost of the network. Based on this estimation, it can then be decided if WiMAX is suitable for the problem considered, and a more in-depth analysis can then be done. Moreover as "Flanders" is very flat, this approach is accurate for a cost estimation [17, 18]. Furthermore, as discussed in Section 3.2, the substations are uniformly distributed over the suburban and rural area of "Flanders". The above described area based algorithm also assumes a uniform distribution as the area considered is divided by the area covered by one base station to calculate the required number of base stations. In this way, it is possible to map a base stations location to a substation site as there can be maximum the same amount of base stations as substations in the area. However, for a more in-depth analysis, a more complex network planning algorithm has to be used such as for e.g. GRAND (Green Radio Access Network Design) [16].

\subsection{Bit rate requirement}

For the monitored data, the collaboration with the power distribution company illustrates that a physical uplink throughput of $64 \mathrm{kbps}$ per substation is sufficient. The lowest modulation scheme (i.e., 1/2 QPSK) supported by WiMAX corresponds with 3.5 Mbps downlink and 2.64 Mbps uplink which is thus sufficient for this case. The physical bit rate is the total number of physically transferred bits per second including useful data as well as the protocol overhead. An uplink of $2.64 \mathrm{Mbps}$ allows 41 modems (=2.64 Mbps/64 kbps) per sector to send their 
data simultaneously to the nearest base station. As a base station typically has three sectors, this results in a total of 123 modems that can be served simultaneously by one base station. Even if a higher amount of modems needs to be connected to one base station, an uplink of $2.64 \mathrm{Mbps}$ will be sufficient as it is not necessary that all modems send their data simultaneously but rather on a timely basis (for e.g., every 10 minutes, quarter or even half hour). A suitable transmission scheme can thus be developed for the modems connected to a base station. The development of such a transmission scheme is however beyond the scope of this study.

Using a higher modulation scheme (resulting thus in a higher offered bit rate which is actually not necessary as described above) is not interesting, because this can lead to a decrease of the signal's robustness and thus to a lower coverage.

In the scenario considered, the Cat. 1 and Cat. 2 BSs are used to cover "Flanders" for $90 \%$ which is a typical value when deploying networks. This means that $10 \%$ of the distribution substations will not be covered by the developed network and thus needs to be connected in a different way. This is however beyond the scope of this study.

\section{RANGE AND COVERAGE}

In this section, it is discussed how a base station's range is determined. Furthermore, it is calculated how much base stations are needed to cover "Flanders". The sensitivity of these results is also investigated.

\subsection{Determination of a base station's range}

To determine the coverage of a base station, a link budget has to be calculated. A link budget takes into account all of the gains and the losses that occur from the transmitter, through the medium, to the receiver [16]. Table II gives an overview of the most important parameters [16, 19]. More information about these parameters can be found in [16]. Note that it is assumed that the input power of both the base stations and the modem is $35 \mathrm{dBm}$. In this way, our coverage investigation is representative for both downlink and uplink. Furthermore, it is assumed that the antennas are placed outdoor (building penetration loss $=0 \mathrm{~dB}$ ).

Based on this link budget, the maximum allowable path loss $\mathrm{PL}_{\max }$ to which a transmitted signal can be subjected while still being detectable at the receiver is calculated [16]. The path loss is the ratio of the transmitted power to the received power of the signal and includes all of the possible elements of loss associated with interactions between the propagating wave and any objects between the transmitter and the receiver. Based on $\mathrm{PL}_{\max }$, the range of the base station can be calculated by using a propagation model. As "Flanders" is mainly flat, the Erceg C model is used in this study [19, 20]. For this model, appropriate parameters are defined, which take

\begin{tabular}{|l|c|}
\hline Parameter & Value \\
\hline Frequency & $3.5 \mathrm{GHz}$ \\
\hline Input power of the BS & $35 \mathrm{dBm}$ \\
\hline Input power of the modem & $35 \mathrm{dBm}$ \\
\hline Antenna gain BS & $18 \mathrm{dBi}$ \\
\hline Antenna gain modem & $8 \mathrm{dBi}$ \\
\hline Feeder loss BS & $0.5 \mathrm{~dB}$ \\
\hline Feeder loss modem & $0 \mathrm{~dB}$ \\
\hline Fade margin & $10 \mathrm{~dB}$ \\
\hline Yearly availability & $99.995 \%$ \\
\hline Interference margin & $0 \mathrm{~dB}$ \\
\hline Bandwidth & $5 \mathrm{MHz}$ \\
\hline Physical bit rate & $3.5 \mathrm{Mbps}$ \\
\hline Receiver SNR & $6 \mathrm{~dB}$ \\
\hline Noise figure of modem & $4.6 \mathrm{~dB}$ \\
\hline Implementation loss modem & $0 \mathrm{~dB}$ \\
\hline Building penetration loss & $0 \mathrm{~dB}$ \\
\hline
\end{tabular}

Table II. Characteristics of the WiMAX system considered.

account for the suburban and rural character of areas. So the Erceg $\mathrm{C}$ model can be used for both the suburban and the rural area.

\subsection{Results}

It is now investigated what the range of the different categories of base stations is. Based on these results, it is determined how much base stations of each category are needed to cover "Flanders". Furthermore, it is studied how sensitivity these results are for changes in the technical parameters.

\subsubsection{Range for the different categories of base stations}

In this section, the range for each category of base station is determined by following the procedure described above. Table III lists the ranges for the Cat. 1 and Cat. 2 BS in the suburban and rural area.

As shown in Table III, the range is higher in the rural area than in the suburban area. This is due to the fact that in the suburban area more objects are present on the line between the transmitter and the receiver. These objects can disturb the quality of the signal resulting in a lower range.

Furthermore, the wireless ranges of Table III are higher than the average distances between two distribution substations, namely $0.36 \mathrm{~m}(<0.56 \mathrm{~m})$ in the suburban area and $0.62 \mathrm{~m}(<0.67 \mathrm{~m})$ in the rural area and it is possible for the Cat. 2 BSs to hop to each other.

\subsubsection{Coverage of "Flanders"}

The number of Cat. 1 and Cat. 2 BSs used to cover "Flanders" for $90 \%$ is shown in Table IV. The suburban area can be covered by using 87 Cat. 1 BSs, no Cat. 2 BSs are needed here (no hopping model required). The rural area is covered by using 444 Cat. 1 BSs. Again, no Cat. 2 


\begin{tabular}{|l|c|c|c|c|}
\hline Cat. BS & Transmitter height [m] & Receiver height [m] & \multicolumn{2}{|c|}{ Range [km] } \\
& & & Suburban & Rural \\
\hline Cat. 1 BS & 30 & 2.5 & 1.82 & 2.41 \\
\hline Cat. 2 BS & 6 & 2.5 & 0.56 & 0.67 \\
\hline
\end{tabular}

Table III. Range of Cat. 1 and Cat. 2 base stations for the different areas.

BSs are needed. In total, 531 Cat. 1 BSs and 0 Cat. 2 BSs are needed to cover "Flanders" for $90 \%$.

\begin{tabular}{|l|c|c|c|}
\hline Cat. BS & Suburban & Rural & Total \\
\hline Cat. 1 BS & 87 & 444 & 531 \\
\hline Cat. 2 BS & 0 & 0 & 0 \\
\hline
\end{tabular}

Table IV. Number of Cat. 1 and Cat. BSs used to cover "Flanders" for $90 \%$.

\subsection{Sensitivity of the results}

In this section, it is investigated how sensitive the results are for changes in maximum allowable path loss $\mathrm{PL}_{\max }$. Section 5.4 will investigate the sensitivity of the cost parameters. The fluctuations in $\mathrm{PL}_{\max }$ can be caused by differences between the assumed parameter values of Table II and the actual values. For example, an antenna gain which is $\mathrm{x}\left(\mathrm{x} \in \Re^{+}\right) \mathrm{dBi}$ lower, resp. higher, than the antenna gain assumed lowers, resp. increases, $\mathrm{PL}_{\max }$ with $x \mathrm{~dB}$. Analogously, when the actual input power of the BS or modem is $\mathrm{x} \mathrm{dB}$ lower, resp. higher, than assumed, $\mathrm{PL}_{\max }$ lowers, resp. increases, with $\mathrm{x} \mathrm{dB}$. Also the height of the BS or modem has an influence on the path loss.

Here, $\mathrm{PL}_{\max }$ is increased and decreased by 5 and $10 \mathrm{~dB}$, which is a realistic variation for the cumulative differences in antenna gain, input power, BS and modem heights, etc. The influence on the range and thus the number of base stations needed to cover "Flanders" is studied. Fig. 3 shows the range of the Cat. 1 and Cat. 2 BSs when PL $\max$ is increased and decreased with $5 \mathrm{~dB}$ and $10 \mathrm{~dB}$. The ranges increase with $18 \%$ to $32 \%$, resp. $39 \%$ to $75 \%$, when the maximum allowable path loss $\mathrm{PL}_{\max }$ is increased with $5 \mathrm{~dB}$, resp. $10 \mathrm{~dB}$ and the ranges decrease with $14 \%$ to $24 \%$, resp. $28 \%$ to $43 \%$ when $\mathrm{PL}_{\max }$ is decreased with $10 \mathrm{~dB}$.

Table V shows the influence of variations in $\mathrm{PL}_{\max }$ on the number of Cat. 1 and Cat. 2 BSs to cover "Flanders" for $90 \%$. When the maximum allowable $\mathrm{PL}_{\max }$ is increased with 5 resp. $10 \mathrm{~dB}$, the number of Cat. 1 BSs decreases with $43 \%$ resp. $67 \%$ and no Cat. 2 BSs are even needed. When $\mathrm{PL}_{\max }$ is decreased with 5 resp. $10 \mathrm{~dB}$, the number of Cat. 1 and Cat. 2 BSs is significantly higher $(2628 \%$ resp. $5642 \%$ due to the high amount of Cat. 2 BSs) than needed in the reference scenario of Section 4.2.2. It is thus very important to make a good and realistic estimation of the parameter values of Table II as small differences in these values can lead to significantly different results.
Note that when the path loss is 5 or $10 \mathrm{~dB}$ lower than predicted, the number of Cat. 2 BS becomes extremely high. Therefore, in practice, the solution would be to increase the antenna height of the Cat. 2 BS. For example, when both the Cat. 1 and the Cat. 2 BS have an antenna height of $30 \mathrm{~m}, 1033 \mathrm{BSs}$ will be needed in total to cover "Flanders" when PL $\mathrm{Pax}_{\max }$ is decreased with $5 \mathrm{~dB}$ and $1799 \mathrm{BSs}$ in total when $\mathrm{PL}_{\max }$ is decreased with $10 \mathrm{~dB}$. Clearly, in this case, the only difference between the Cat. 1 and Cat. 2 BS is that the Cat. 1 BSs have backhaul connections.

\section{COST CALCULATIONS}

In this section, the deployment costs of the network are investigated. Many costs are involved when rolling out such a network. In this section, an overview is given of all these costs. Furthermore, the sensitivity of the total cost for changes in individual costs is investigated.

\subsection{Base station costs}

In this section, the cost for the different categories of base stations is determined based on [21, 22, 23]. These values are updated based on private interviews with several equipment vendors and operators. Table VI shows the cost break-up for the two categories of base stations. First, the BS equipment needs to be purchased (Section 3.2). This results in a total cost of 24,000 EUR for both the Cat. 1 and Cat. 2 BSs. There is no difference in this cost between the two categories of base stations as it is assumed that their only difference is the antenna height and not their functionality. Note that the costs for the backhauling connection is not included as this connection will be provided by the utility company. The second cost that is taken into account is the cost for the antennas. A base station typically has three antennas i.e., one antenna per sector each covering $120^{\circ}$ [16]. Assuming a cost of 1,000 EUR for one antenna results in a total cost of 3,000 EUR for both categories of base stations. Furthermore, a pole is needed for the installation of the antennas. For a Cat. $1 \mathrm{BS}$, a $30 \mathrm{~m}$ pole is needed with a cost of 16,000 EUR, while for the Cat. 2 BS, a $6 \mathrm{~m}$ pole is used with a lower cost of 4,000 EUR. For placing such poles, a building permission is obliged. Based on information about the license to build a windmill, a cost of 5,000 EUR was derived for the Cat. 1 BS and 500 EUR for the Cat. 2 BS. The cost of the license itself is very 


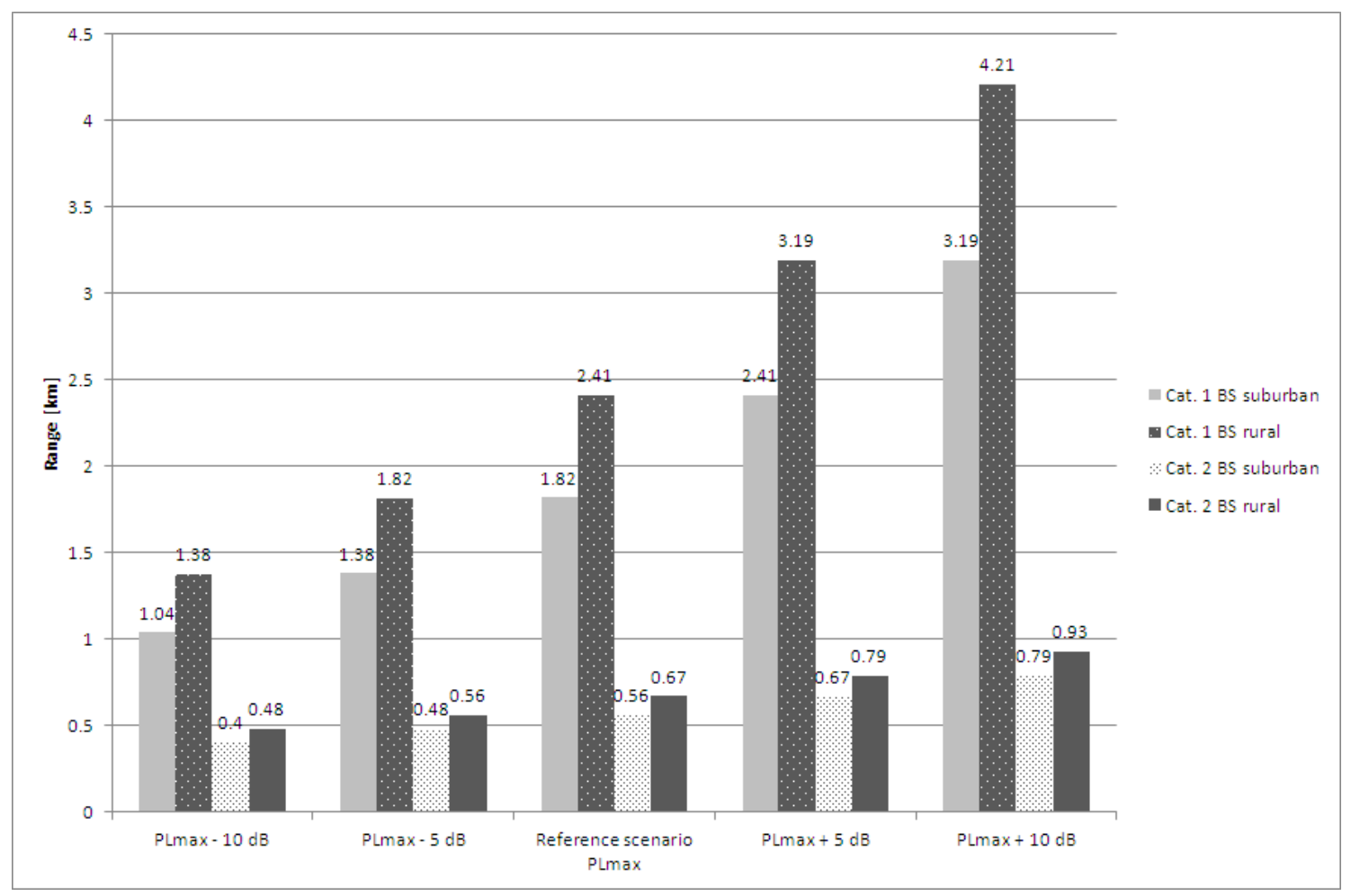

Figure 3. Range of the Cat. 1 and Cat. $2 \mathrm{BS}$ when $\mathrm{PL}_{\max }$ is increased/decreased with 5 and $10 \mathrm{~dB}$.

\begin{tabular}{|l|c|c|c|c|c|}
\hline $\mathbf{P L}_{\max }$ & $\mathbf{+ 5} \mathbf{d B}$ & $\mathbf{+ 1 0 ~ d B}$ & $\mathbf{0 ~ d B}$ & $\mathbf{- 5} \mathbf{~ d B}$ & $\mathbf{- 1 0 ~ d B}$ \\
\hline Cat. 1 BS & 304 & 175 & 531 & 600 & 600 \\
\hline Cat. 2 BS & 0 & 0 & 0 & 13888 & 29820 \\
\hline Deviation & $-43 \%$ & $-67 \%$ & - & $+2628 \%$ & $+5642 \%$ \\
\hline
\end{tabular}

Table V. Total number of Cat. 1 and Cat. 2 BSs used to cover "Flanders" for $90 \%$ when $\mathrm{PL}_{\max }$ is increased and decreased with 5 and $10 \mathrm{~dB}$ and the deviation of $\# \mathrm{BS}$ with respect to $\mathrm{PL}_{\max }+0 \mathrm{~dB}$.

limited (between 10 and 50 EUR), but the research into the suitability of each location is very time consuming. A $30 \mathrm{~m}$ pole is more drastic for the landscape view and therefore its cost is significantly higher than for a $6 \mathrm{~m}$ pole. Finally, the antennas and the pole need to be installed. A cost of 3,000 EUR for a Cat. 1 BS and 500 EUR for a Cat. 2 BS is considered. The antenna installation cost for a Cat. $1 \mathrm{BS}$ is of course higher than for a Cat. 2 BS as it has a higher antenna height. A total of 51,000 EUR for a Cat. $1 \mathrm{BS}$ and 30,000 EUR for a Cat. 2 BS is thus found for the CapEx (Capital Expenditures) costs.

Besides the initial CapEx costs, there is also the costs for yearly maintenance and licensing. The yearly maintenance cost is estimated at $10 \%$ of the initial cost. Also the license fee for the use of the WiMAX frequencies has to be paid yearly. As mentioned above, each base station supports three sectors which implies the use of 3 channels of $5 \mathrm{MHz}$ bandwidth. Based on the costs that the WiMAX operator Clearwire has paid (i.e., 349 EUR/MHz/BS), a yearly cost of approximately 5,000 EUR for each base station is estimated. The total OpEx (Operational Expenditures) amount thus to 10,100 EUR for a Cat. 1 BS and 8,000 EUR for a Cat. 2 BS.

\begin{tabular}{|l|c|c|}
\hline Cost item & Cat. 1 BS & Cat. 2 BS \\
\hline Equipment & 24 kEUR & 24 kEUR \\
\hline Antenna (3) & $3 \mathrm{kEUR}$ & $3 \mathrm{kEUR}$ \\
\hline Pole & $16 \mathrm{kEUR}$ & $4 \mathrm{kEUR}$ \\
\hline Antenna installation & $3 \mathrm{kEUR}$ & $0.5 \mathrm{kEUR}$ \\
\hline Building permission & $5 \mathrm{kEUR}$ & $0.5 \mathrm{kEUR}$ \\
\hline Total CapEx & $\mathbf{5 1 ~ k E U R ~}$ & $\mathbf{3 0}$ kEUR \\
\hline \hline Maintenance & $5.1 \mathrm{kEUR}$ & $3 \mathrm{kEUR}$ \\
\hline WiMAX license & $5 \mathrm{kEUR}$ & $5 \mathrm{kEUR}$ \\
\hline Total OpEx & $\mathbf{1 0 . 1}$ kEUR & $\mathbf{8}$ kEUR \\
\hline
\end{tabular}

Table VI. Cost overview for Cat. 1 and Cat. 2 BS. 


\subsection{Modem costs}

As mentioned above, each transformer substation will be equipped with a modem. Therefore, a total of 40,000 modems needs to be installed across "Flanders". In [21], the modem was considered as user equipment. However, in this case, the modems will be deployed by the utility company and thus an in-depth investigation of its cost is necessary. Table VII shows the cost break-up for the modem. The functionality of these modems is very standard and the cost of one modem is thus estimated at 200 EUR. This amount is based on the price of the modems of different vendors currently found on the market. 200 EUR may appear rather high, but a high quality modem is needed to avoid costly and lengthy repair and replacement procedures. For the installation of the modem, dedicated personnel is used which are working from a central point in "Flanders". Furthermore, it is assumed that substations which are physically close together are equipped with a modem on the same day. Therefore, a round-trip of on average $120 \mathrm{~km}$ (which is approximately the distance from the central point in "Flanders" to any other region in "Flanders") is assumed. When considering a tariff of $0.3 \mathrm{EUR} / \mathrm{km}$, the transportation cost per day amounts to 36 EUR. This round-trip takes close to two hours. Assuming a 8 hour work day and an hourly wage of 30 EUR per person, this leads to a daily cost of 240 EUR per installer. In the remaining 6 hours, it is estimated that 4 different modems can be installed. The average cost $\mathrm{Cmi}$ per modem installation (in EUR) can thus be calculated as follows:

$$
C m i=(D p d \cdot K m c+H p d \cdot W p h) / M p d
$$

with $D p d$ the average distance per day per installer (in $\mathrm{km}$ ), $K m c$ the tariff per $\mathrm{km}$ (in EUR/km), Hpd the hours worked per day by the installer (in hours), $W p h$ the wage per hour of the installer (in EUR/hour), and $M p d$ the number of modems installed per day by one installer. This leads to an average cost of 69 EUR per installed modem.

\begin{tabular}{|l|c|}
\hline Cost item & Modem \\
\hline Equipment & 200 EUR \\
\hline Installation & 70 EUR \\
\hline Total CapEx & $\mathbf{2 7 0}$ EUR \\
\hline Cost per failure & 224 EUR \\
\hline
\end{tabular}

Table VII. Cost overview for the modem.

For the maintenance costs of the modem, the same two components are considered i.e., the transportation and the personnel cost. However, in this case, the transportation has to be made for each modem separately. Moreover, in $50 \%$ of the failures, it is assumed that it is better to completely replace the modem instead of repairing it. In general, the MTBF (Mean Time Between Failures) for routers and modems is in the order of 200,000 hours, or thus an average failure rate of $4 \%$. This only contains hardware failures, so here a failure rate of $8 \%$ (50\% of these failures are hardware failures) is considered. Nonhardware failures could be e.g. related to software bugs. This leads to an average cost of 224 EUR per failure calculated by the following formula:

$$
C m f=D p f \cdot K m c+H p f \cdot W p h+P h w \cdot C m
$$

with $C m f$ the average cost per modem failure (in EUR), $D p f$ the average distance per failure, $K m c$ the tariff per $\mathrm{km}, H p f$ the hours worked per failure by the installer (including transport), Wph the wage per hour of the installer (in EUR/hour), Phw the probability of a hardware failure (in \%), and $\mathrm{Cm}$ the cost of a modem.

\subsection{Results}

In this section, the cost for the complete network is determined based on the input of the above sections. The cost here considered is the Net Present Cost (NPC) of the project over 5 years, with a discount rate of 5.5\% and represents the total current cost based on all expected future costs during the project life-span. The results of Section 4.2.2 are here used as input.

Fig. 4 shows the cost break-up and evolution of the reference scenario, discussed in Section 4.2.2. Year 0 is the time of roll-out and includes the initial CapEx investments. The following years include the OpEx costs. Summing up all the costs leads to a NPC of 63.8 million EUR (over 5 years). Note that the poles still have a value after 5 years, which is however hard to estimate. Applying the accounting rule of writing off the value linearly according to the useful life (estimated at 20 years), a residual value of about 6 MEUR is to be expected.

\subsection{Sensitivity of the results}

In this section, it is investigated how changes in the technical and cost parameters influence the cost calculations. First, it is studied how the technical parameters influence the cost calculations. Second, the influence of the cost parameters on the total cost is studied.

\subsubsection{Influence of the technical parameters}

For this study, the results from Section 4.3 are used as input. Fig. 5 shows the NPC of the project over 5 years with a discount rate of $5.5 \%$ when the maximum allowable path loss $\mathrm{PL}_{\max }$ is increased and decreased with 5 and $10 \mathrm{~dB}$. When $\mathrm{PL}_{\max }$ is increased with $5 \mathrm{~dB}$, resp. $10 \mathrm{~dB}$, the total cost decreases with $33.5 \%$, resp. $52.5 \%$ due to the lower number of Cat. 1 BS needed for these scenarios (Section 4.3). The total cost is thus non-linearly impacted by changes in the $\mathrm{PL}_{\max }$. When $\mathrm{PL}_{\max }$ is decreased with $5 \mathrm{~dB}$, resp. $10 \mathrm{~dB}$, the cost increases with $1405.9 \%$, resp. $3007.0 \%$ due to the very high number of Cat. 2 BS that need to be used to cover the area.

For comparison, the cost is also compared to the situation where the antenna height of the Cat. $2 \mathrm{BS}$ is raised to $30 \mathrm{~m}$ (i.e., there is no difference any more between the Cat. 1 and Cat. 2 BS, see Section 4.3). In this case, the total 


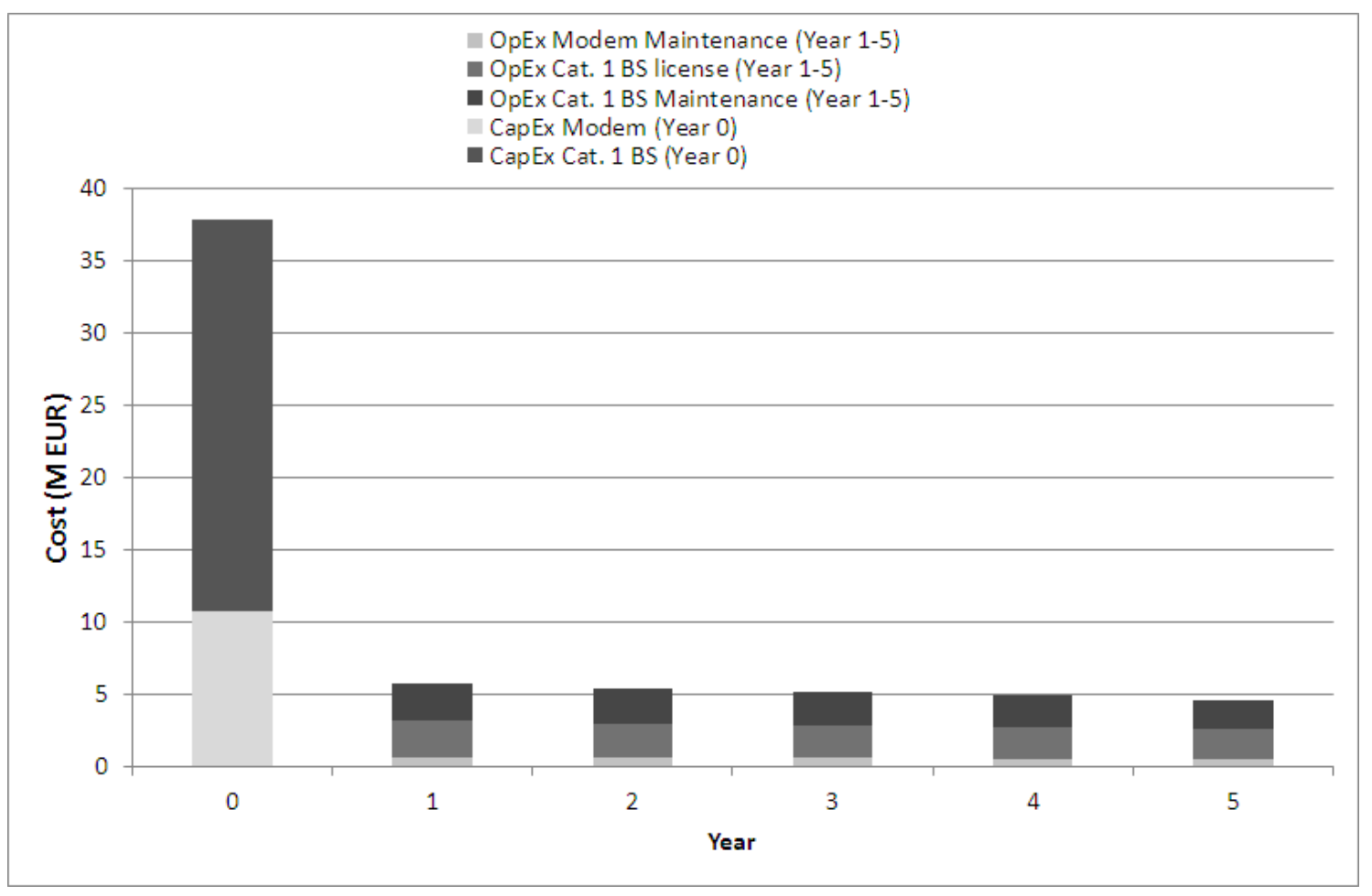

Figure 4. Cost break-up and evolution of reference scenario.

cost increases with only $74.0 \%$ when $\mathrm{PL}_{\max }$ is decreased with $5 \mathrm{~dB}$ and with $187.0 \%$ when PL $\max$ is decreased with $10 \mathrm{~dB}$. However, note that acquiring building permits for $30 \mathrm{~m}$ BSs can be time-consuming or the request may be denied, in which case there is no other option but to use BSs at $6 \mathrm{~m}$.

\subsubsection{Influence of the cost parameters}

In this section, the influence of the cost parameters on the NPC is studied. Again, it is assumed that the project runs over 5 years with a discount rate of $5.5 \%$. Three parameters are investigated: the price of the WiMAX license, the CapEx of the modem, and the CapEx of the Cat. 1 BS. The costs of the first two parameters are changed with $-50 \%$ and $+50 \%$, while the cost of the latter is changed with $-20 \%$ and $+20 \%$. This lower fluctuation represents a lower degree of uncertainty about the actual value of the parameter. Fig. 6 shows the total cost for each case.

Changing the WiMAX license cost with $+50 \%$, resp. $-50 \%$, results in a change of $-8.9 \%$, resp. $+8.9 \%$, for the total project cost. Analogously, changing the modem CapEx with $50 \%$ results in a change of $8.5 \%$ for the total project cost. Finally, when the CapEx of the Cat. 1 BS is increased, resp. decreased, with $20 \%$, the total cost increases, resp. decreases, with $12.1 \%$. Although the change of the parameter is lower than for the other two parameters considered, it still results in a higher change of the total cost. This is due to the fact that the CapEx of the
Cat. 1 BS is responsible for a big part of the total cost as shown in Fig. 4.

\subsubsection{Influence of the technical parameters versus influence of the cost parameters}

Comparing the influence of changes in the technical parameters (Section 5.4.1) and the influence of changes in the cost parameters (Section 5.4.2) on the total project cost, shows that the impact of changes in the cost parameters is considerably lower (8 to $12 \%$ versus $33 \%$ to $3007 \%$ for the technical parameters) than for the technical parameters as also concluded in [23]. Therefore, a reliable estimate of the path loss (possibly through actual measurements on the field) is thus a necessity to perform an accurate network dimensioning and cost calculation.

\section{CONCLUSIONS}

In this study, a monitoring network for the substations of a power distribution company is designed based on the wireless technology WiMAX. Furthermore, the cost to install and maintain the network is also determined. It was found that 531 WiMAX base stations are needed to cover the considered area "Flanders", Belgium, for $90 \%$, leading to a cost of 63.8 MEUR (about 6,380 EUR per $\mathrm{km}^{2}$ ). These results are very sensitive to possible changes of the technical parameters, which lead to cost fluctuations of as much as $33.5 \%$ and $3007 \%$. Therefore, a reliable 
WiMAX Based Monitoring Network for a utility companyM. Deruyck, E. Vanhauwaert, D. Pareit, B. Lannoo, W. Joseph, I. Moerman, L. Martens

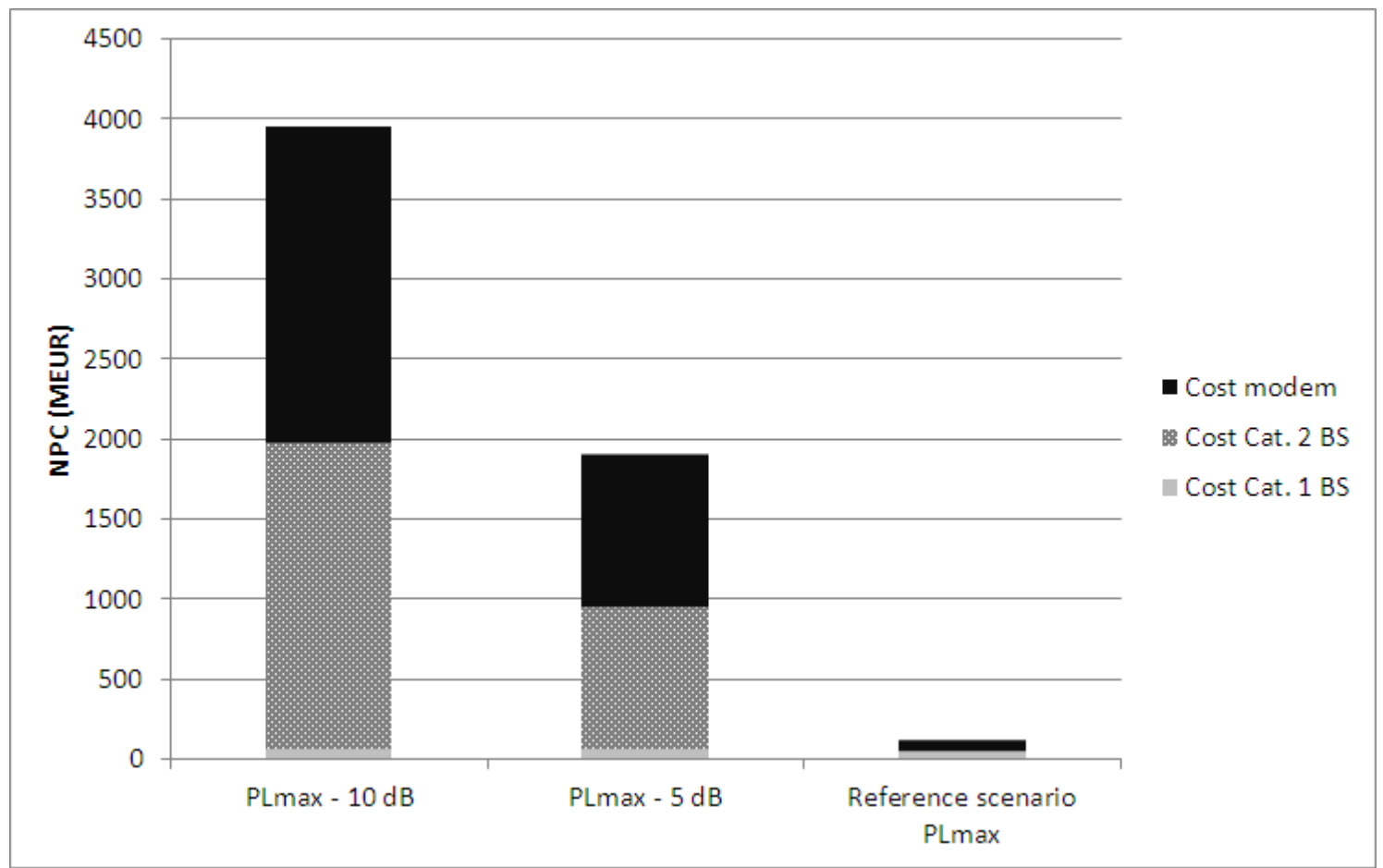

(a)

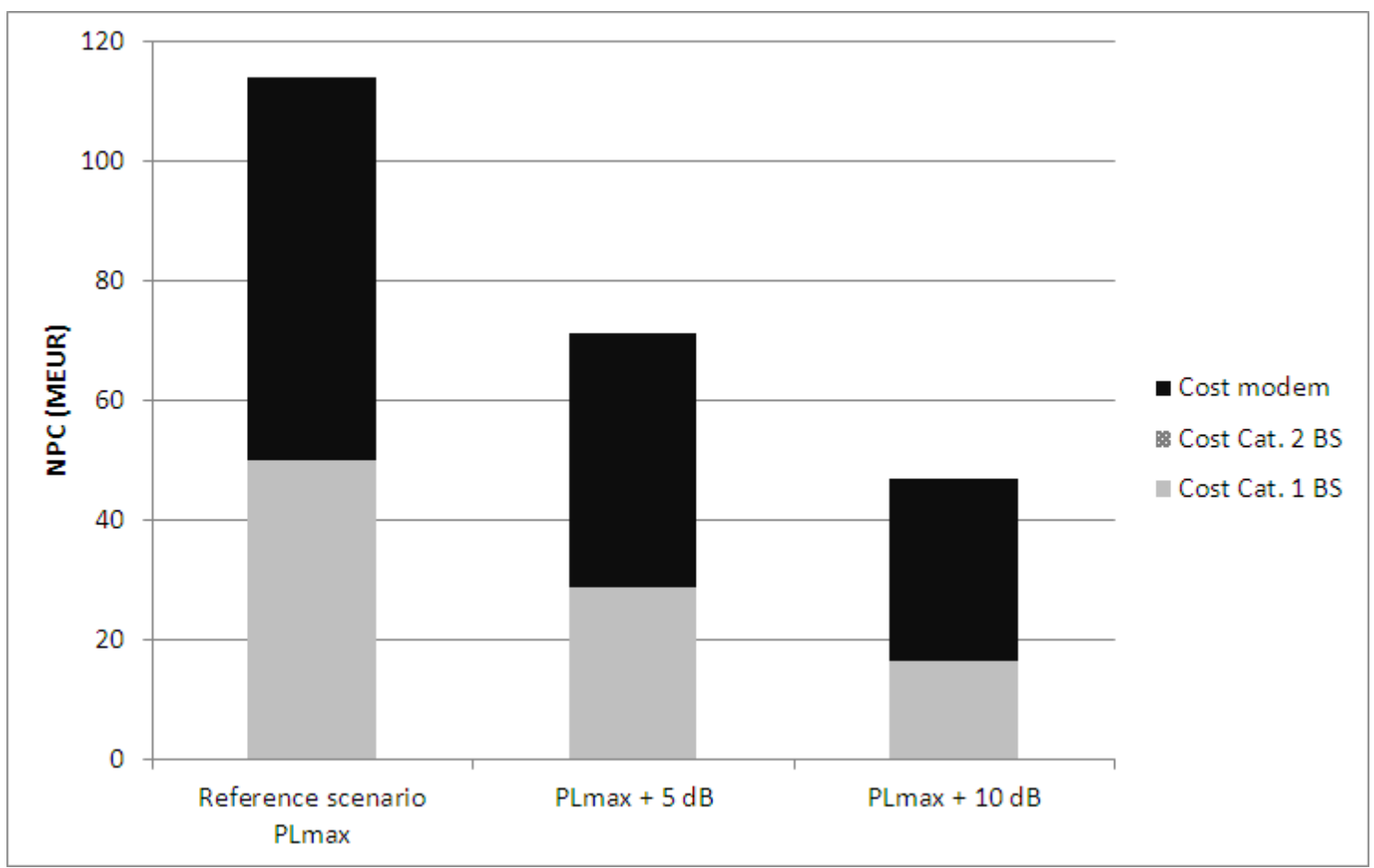

(b)

Figure 5. Influence of the technical parameters on the cost calculations.

estimate of the technical parameters (possibly through

actual measurements on the field) is a necessity to perform an accurate network dimensioning. 


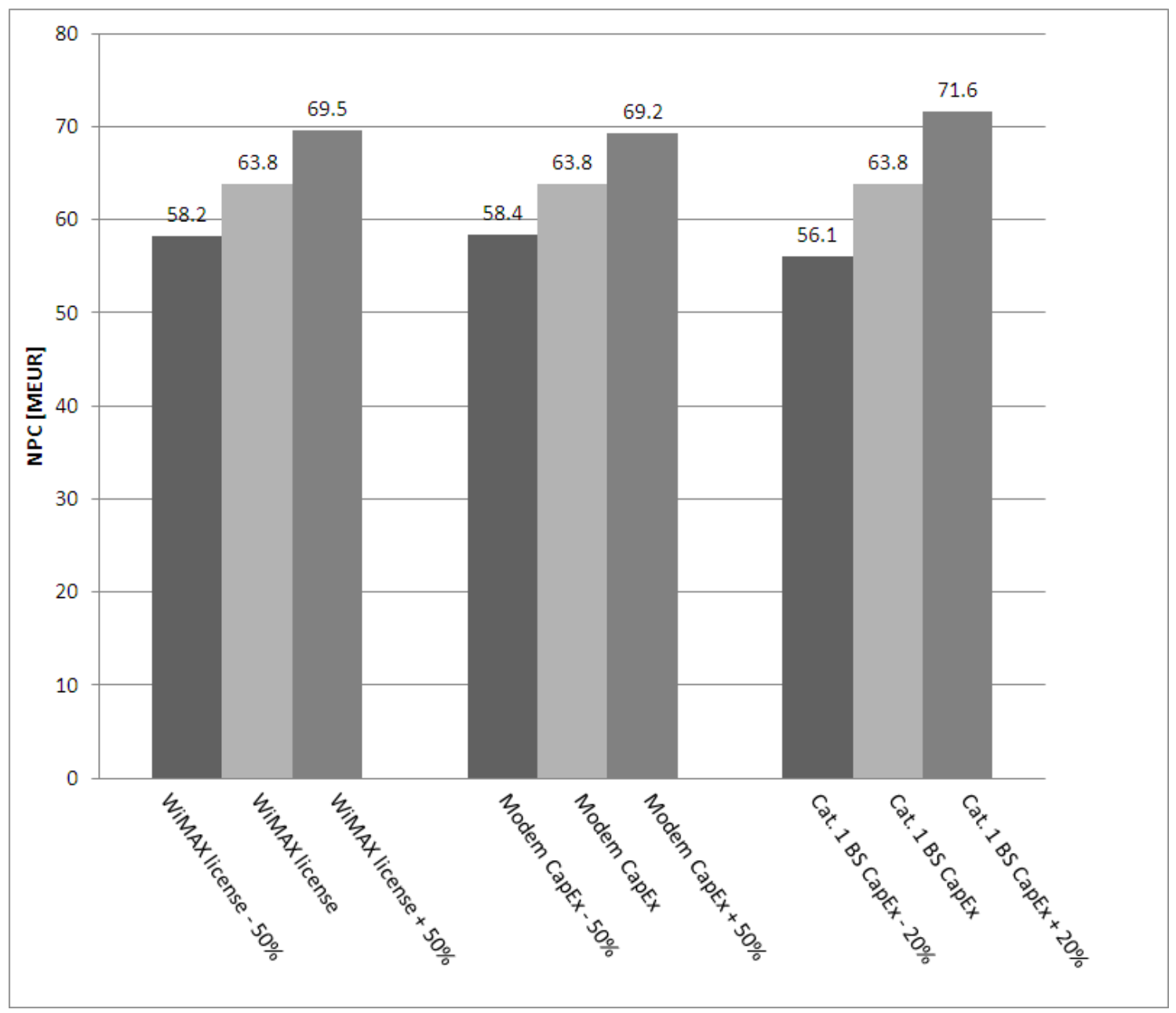

Figure 6. Influence of the cost parameters on the cost calculations.

Changes in the cost parameters have less impact on the total cost. Changes in the CapEx of the base stations have the highest influence on the total cost and leads to a limited fluctation in the NPC (Net Present Cost) of only $12 \%$.

Finally, using BSs with a height of $6 \mathrm{~m}$ is considerably less efficient than using poles of $30 \mathrm{~m}$ as both the number of BSs and the cost rise significantly. For low-bitrate WiMAX networks, it is better to use a low amount of BSs with an antenna height of approximately $30 \mathrm{~m}$ than BSs with an antenna height of approximately $6 \mathrm{~m}$.

\section{ACKNOWLEDGEMENT}

W. Joseph is a Post-Doctoral Fellow of the FWO-V (Research Foundation Flanders).

\section{REFERENCES}

1. W. Joseph, L. Verloock, L. Martens, General Public Exposure by ELF Field of 150-36/11 kV Substations in Urban Environment, IEEE Transactions on Power Delivery, April 2009, pp. 642-649.

2. W. Joseph, L. Verloock, L. Martens, Measurements of ELF electromagnetic exposure of general public from Belgian power distribution substations, Health Phys, Vol. 94, No. 1, January 2008, pp. 57-66.

3. IEEE Standard for Local and Metropolitan Area Networks, Part 16: Air Interface for Broadband Wireless Access Systems, 2009.

4. Quantum, WiMAX networks around the world, http://quantumwimax.com/index.php?page=WimaxNetworks-around-the-world, August 2011.

5. http://www.reuters.com/article/2010/05/21/yota-lteidUSLDE64K1V920100521, accessed June 2012.

6. http://www.dailywireless.org/2012/02/22/yota-plansovernight-swap-from-wimax-to-lte/, accessed June 
2012.

7. http://www.dailywireless.org/2011/04/08/lte-vrswimax-its-a-wrap/, accessed June 2012.

8. MuniWireless, Houston moves city services to municipal wireless network based on WiMAX, http://www.muniwireless.com/2011/03/30/houstonmoves-city-services-to-municipal-wireless-network/, August 2011.

9. W. Eichelberg, Using GPRS to connect outlying distribution substations, 18th International Conference on Electricity Distribution, Turin, 6-9 June 2005, pp. 14.

10. L. Kong, J. Jin, J. Cheng, Introducing GPRS Technology into Remote Monitoring System for Prefabricated Substations in China, 2nd International Conference on Mobile Technology, Applications and Systems, 2005, pp. 1-6.

11. D. Laverty, D.J. Morrow, J. O'Raw, P. A. Crossley, Wireless Telecoms for Distribution Networks based on WiMAX, 20th International Conference on Electricity Distribution, Prague, 8-11 June, 2009, pp. 1-4.

12. T. Godfrey, The Field Area Network - A WiMAX application for Smart Grid, presentation at 2011 Taipei WiMAX Summit.

13. IEEE Computer Society and IEEE Microwave Theory and Techniques Society, Air Interface for Fixed Broadband Wireless Access Systems, October 2004.

14. WiMAX Forum Certified Product Registry, http://wimaxforum.org/certification/certified-productshowcase, January 2011.

15. Statistics Belgium, http://statbel.fgov.be/nl/statistieken/cij January 2011.

16. M. Deruyck, E. Tanghe, W. Joseph, L. Martens, Modelling and optimization of power consumption in wireless access networks, Elsevier Computer Communications, Vol. 34, No. 17, November 2011.

17. W. Joseph, D. Plets, L. Verloock, E. Tanghe, L. Martens, E. Deventer, and H. Gauderis, Procedure to Optimize Coverage and Throughput for a DVB$H$ System Based on Field Trials, IEEE Transactions Broadcasting, Vol. 54, No. 3, September 2008, pp. 347-355.

18. W. Joseph, L. Martens, Performance evaluation of broadband fixed wireless system based on IEEE 802.16, Proceedings of the IEEE Wireless Communications and Networking Conference (WCNC 2006), Vol. 2, April 2006, pp. 978-983.

19. J. De Bruyne, W. Joseph, D. Plets, L. Verloock, E. Tanghe, L. Martens, Comparison of the link budget with experimental performance of a WiMAX system, EURASIP Journal on Wireless Communications and Networking, Vol. 2009.

20. V. Erceg, L. J. Greenstein, S. Y. Tjandra, S. R. Parkoff, A. Gupta, B. Kulic, A. A. Julius, R. Bianchi, An Empirically Based Path Loss Model for Wireless Channels in Suburban Environments, IEEE Journal on Selected Areas in Communications, Vol. 7, No. 7, July
1999, pp. 1205-1211.

21. B. Lannoo, S. Verbrugge, J. Van Ooteghem, B. Quinart, M. Casteleyn, D. Colle, M. Pickavet, P. Demeester, Business Model for a Mobile WiMAX Deployment in Belgium, published in "Mobile WiMAX", Chapter 18, ISBN: 978-0-470-51941-7, John Wiley \& Sons, February 2008, pp. 353-375.

22. J. Van Ooteghem, B. Lannoo, K. Casier, S. Verbrugge, E. Tanghe, W. Joseph, L. Martens, M. Pickavet, I. Moerman, P. Demeester, Municipalities as a Driver for Wireless Broadband Access, Wireless Personal Communications, Vol. 49, No. 3, May 2009, pp. 391414.

23. B. Lannoo, J. De Bruyne, W. Joseph, J. Van Ooteghem, E. Tanghe, D. Colle, L. Martens, M. Pickavet, P. Demeester, Influence of Technical Improvements on the Business Case for a Mobile WiMAX Network, 4th International Conference on Access Networks, Hong Kong, China, 1-3 November, 2009, pp. 52-66.

\section{AUTHORS' BIOGRAPHIES}

Margot Deruyck was born in Kortrijk, Belgium on July 14, 1985. She received her M. Sc. degree in computer science engineering from Ghent University in July 2009. Since September 2009 she has been a research assistant in the Wireless and Cable (WiCa) research group at INTEC UGent/IBBT. Her scientic work is focused on green wireless access networks with minimal power consumption and minimal exposure of humans.

Erik Vanhauwaert received an M.Sc. degree in computer science, specialising in software engineering from Ghent University, Belgium in 2007. He joined Fortis Bank to pursue a management traineeship and returned to the same university at the end of 2009 where he joined the Internet Based Communication Networks and Services (IBCN) group of the Department of Information Technology (INTEC). His current research focuses on techno-economical evaluation of communication networks and services and he is working towards a $\mathrm{PhD}$ in this domain.

Daan Pareit received a M.Sc. degree (2006) in Electrotechnical Engineering, with ICT as main subject, and a Ph.D. degree (2011) in Computer Science Engineering from Ghent University (UGent, Belgium). In August 2006, he joined the Information Technology department (INTEC) of Ghent University. Within this department, he is working at the Internet Based Communication Networks and Services research group (IBCN). As a member of this research group, he is also affiliated with the Interdisciplinary institute for BroadBand Technology (IBBT). He studied the interworking of heterogeneous wireless networks for moving users, and for trains in particular within project ICON-TRAINS and 
ICON-TRACK. He was granted a Ph.D scholarship from the Institute for Promotion of Innovation through Science and Technology in Flanders (IWT-Vlaanderen) during 2007-2010 to elaborate this topic.

Bart Lannoo received a M.Sc. degree in electrotechnical engineering and a Ph.D. degree from Ghent University (Belgium) in July 2002 and May 2008, respectively. Since August 2002, he has been working at the Internet Based Communication Networks and Services (IBCN) research group of the Department of Information Technology (INTEC) of Ghent University, where he is currently a postdoctoral researcher. As a member of the IBCN research group, he is also affiliated with the Interdisciplinary institute for BroadBand Technology (IBBT). His research deals with fixed and wireless access networks, focusing on MAC protocols, Green ICT and techno-economics. He has been involved in various national and European research projects, like the FP6 project IST-BREAD and the FP7 project ICT-ALPHA. Currently he is active in the European FP7 project ICTOASE and coordinating the IBBT project GreenWeCan.

Wout Joseph received his M. Sc. degree in electrical engineering from Ghent University (Belgium) in July 2000. From September 2000 to March 2005, he was a research assistant at the Department of Information Technology (INTEC) of the same university. During this period, his scientific work was focused on electromagnetic exposure assessment. His research work dealt with measuring and modelling of electromagnetic fields around base stations for mobile communications related to the health effects of the exposure to electromagnetic radiation. This work led to a $\mathrm{Ph}$. D. degree in March 2005. Since April 2005, he is postdoctoral researcher for IBBT-Ugent/INTEC (Interdisciplinary institute for BroadBand Technology). Since October 2007, he is a Post-Doctoral Fellow of the FWO-V (Research Foundation Flanders). Since October 2009 he is professor in the domain of Experimental Characterization of wireless communication systems. His professional interests are electromagnetic field exposure assessment, propagation for wireless communication systems, antennas and calibration. Furthermore, he specializes in wireless performance analysis and Quality of Experience.

Ingrid Moerman received her degree in Electrical Engineering (1987) and the PhD degree (1992) from the Ghent University, where she became a part-time professor in 2000. She is a staff member of the research group Internet Based Communication Networks and Services (IBCN), where she is leading the research on mobile and wireless communication networks. Since 2006 she joined the Interdisciplinary institute for BroadBand Technology (IBBT), where she is coordinating several interdisciplinary research projects. Her main research interests include: wireless broadband networks for fast moving users, mobile ad hoc networks, personal networks, self-organizing distributed networks, network virtualization, wireless body area networks, wireless sensor and actuator networks, wireless mesh networks, QoS support in mobile \& wireless networks, vehicle-to-vehicle and vehicle-toinfrastructure networks for intelligent transport systems, self-optimization in next-generation wireless networks, network architectures and protocols for heterogeneous mobile and wireless networks. She is author or coauthor of more than 400 publications in international journals or conference proceedings.

Luc Martens was born in Ghent, Belgium on May 14, 1963. He received the MSc degree in electrical engineering and a $\mathrm{PhD}$ degree in development of a multichannel hyperthermia system: electromagnetic modeling of applicators, generator design, and estimation algorithms for thermometry from Ghent University (Belgium), in July 1986 and December 1990, respectively. From September 1986 to December 1990, he was a research assistant at the Department of Information Technology (INTEC), Ghent University. Since January 1991, he has been a member of the permanent staff of the Interuniversity MicroElectronics Center (IMEC), Ghent and is responsible for the research on experimental characterization of the physical layer of telecommunication systems at INTEC. Since April 1993, he has been a professor of electrical applications of electromagnetism at Ghent University. 